Supporting Information

\title{
Directional Propulsion of DNA Microspheres Based on Light-Induced Asymmetric Growth of Peptide Nanofiber
}

Hiroshi Inaba, ${ }^{* 1,2}$ Kenji Hatta, ${ }^{1}$ Kazunori Matsuura*1,2

${ }^{1}$ Department of Chemistry and Biotechnology, Graduate School of Engineering, Tottori University, Tottori 680-8552, Japan.

${ }^{2}$ Centre for Research on Green Sustainable Chemistry, Tottori University, Tottori 680-8552, Japan.

Corresponding Authors

*E-mail: hinaba@tottori-u.ac.jp

*E-mail: ma2ra-k@tottori-u.ac.jp 
(a)

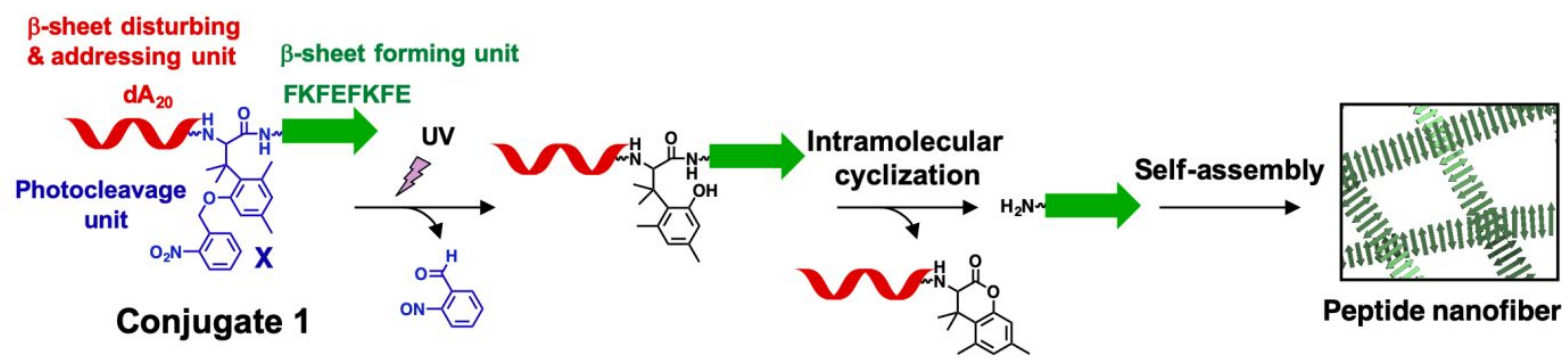

(b)

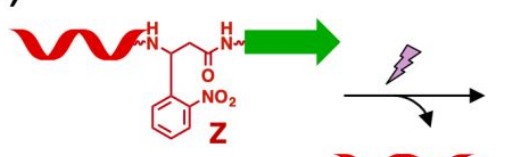

Conjugate 2

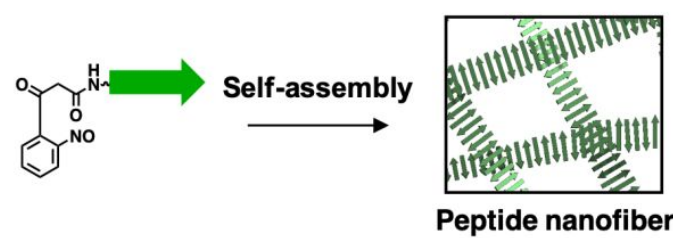

Peptide nanofiber

(c) This work

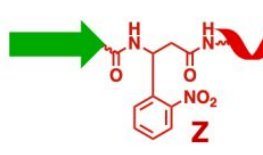

Conjugate 3

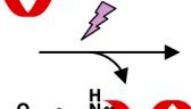

$\sin ^{\mathrm{No}}$
Self-assembly

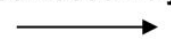

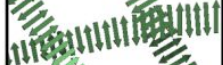

Peptide nanofiber

Figure S1. Comparison of UV light-induced peptide nanofiber growth of peptide-DNA conjugate (a) 1 , (b) 2 , (c) 3 .
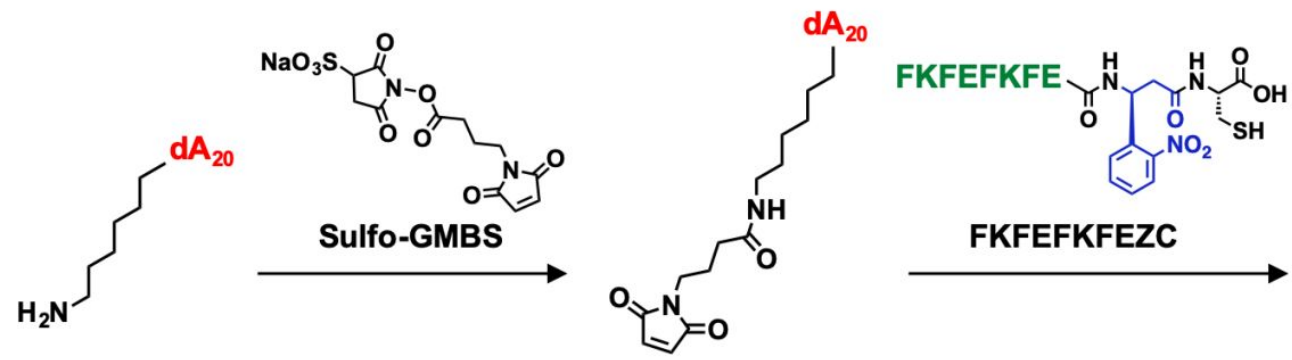

\section{FKFEFKFEZC}

$d \mathrm{~A}_{20}-\mathrm{NH}_{2}$

$\mathbf{d A}_{20}$-maleimide

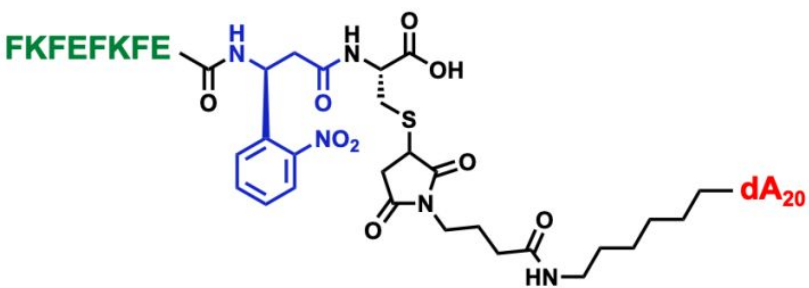

Conjugate 3

Figure S2. Scheme of synthesis of conjugate 3 . 


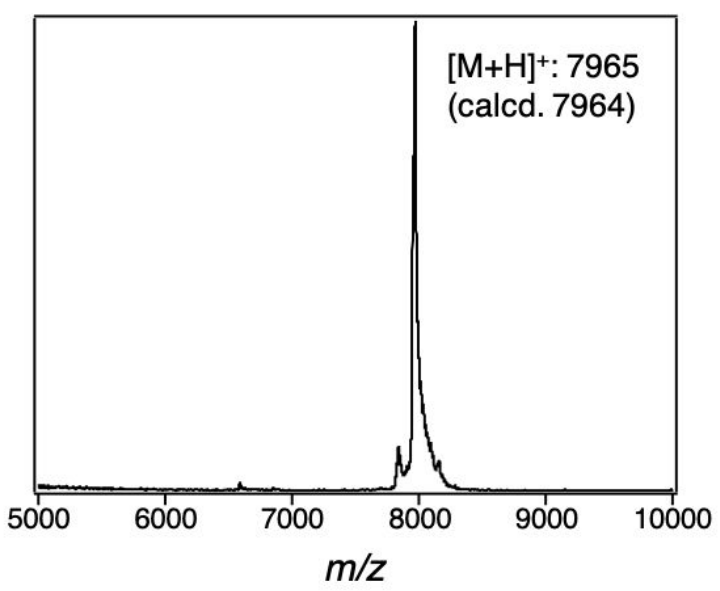

Figure S3. MALDI-TOF-MS of conjugate 3 (matrix: 3-hydroxypicolinic acid).
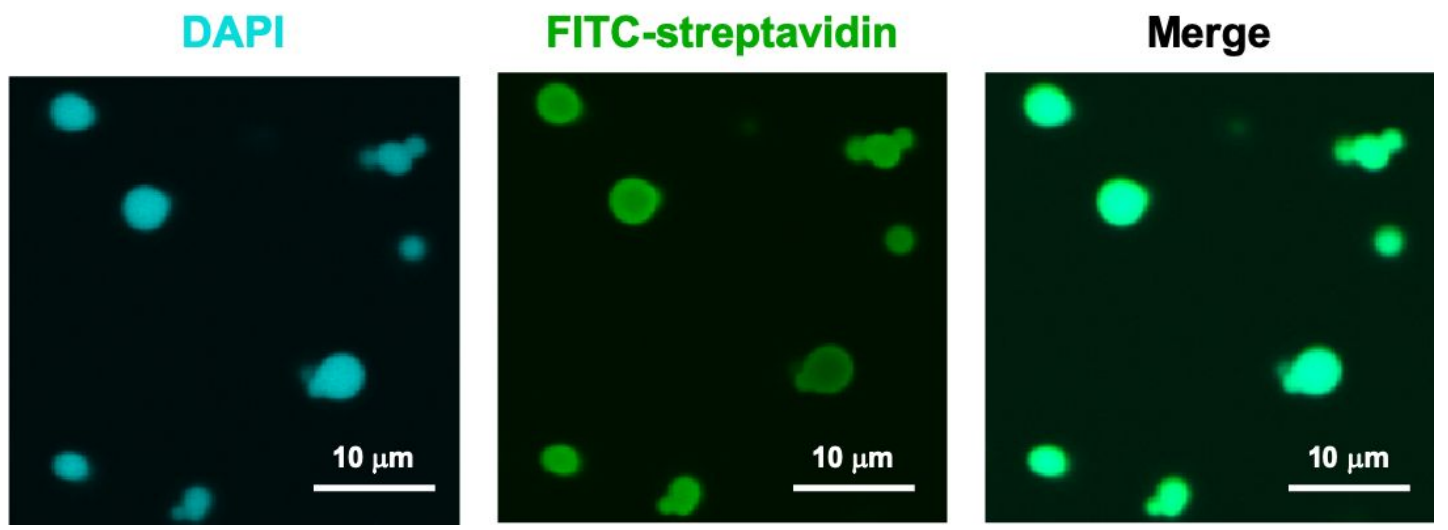

Figure S4. CLSM images of nucleospheres stained with DAPI and FITC-streptavidin. Final concentrations: $[$ Total ssDNAs] $=2.7 \mu \mathrm{M}$, [FITC-Streptavidin] $=0.3 \mu \mathrm{M}$, and [DAPI] $=0.58 \mu \mathrm{M}$.

Table S1. Diameter of nucleospheres used for the microscope observation. The data represent average \pm standard deviation.

\begin{tabular}{|l|l|l|l|}
\hline Entry & Sample & Light & Diameter $(\boldsymbol{\mu m})$ \\
\hline 1 & 3-NS $(15.6 \mu \mathrm{M} \mathrm{3})$ & + & $3.8 \pm 0.5$ \\
\hline 2 & 3-NS $(3.1 \mu \mathrm{M} \mathrm{3})$ & + & $3.6 \pm 0.3$ \\
\hline 3 & $3-N S(0.31 \mu \mathrm{M} \mathrm{3})$ & + & $3.5 \pm 0.6$ \\
\hline 4 & $3-N S(15.6 \mu \mathrm{M} \mathrm{3})$ & - & $3.4 \pm 0.4$ \\
\hline 5 & $\mathrm{dA}_{20}-\mathrm{NS}$ & + & $3.6 \pm 0.5$ \\
\hline
\end{tabular}




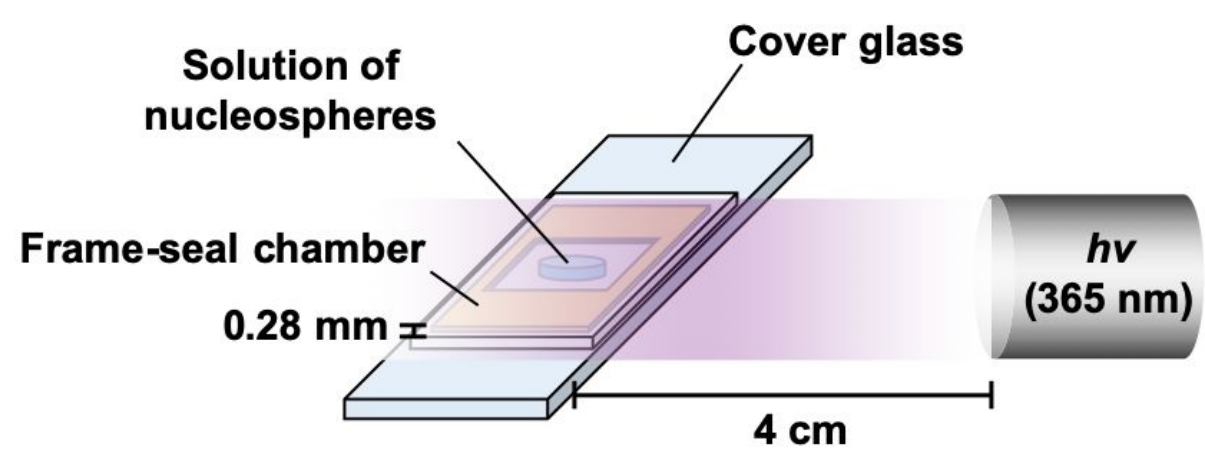

Figure S5. Schematic illustration of an observation system of nucleospheres under UV light irradiation.

(a) 3-NS (3.1 $\mu \mathrm{M} 3)$, +light

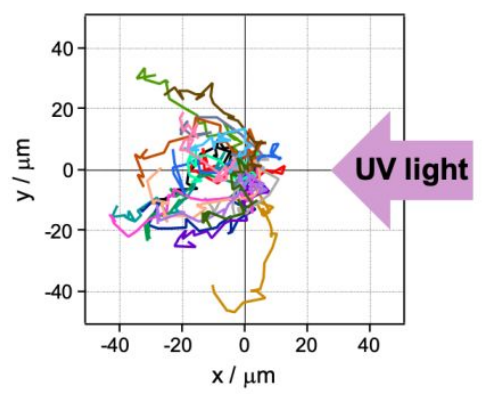

(b) 3-NS $(0.31 \mu \mathrm{M} 3)$, +light

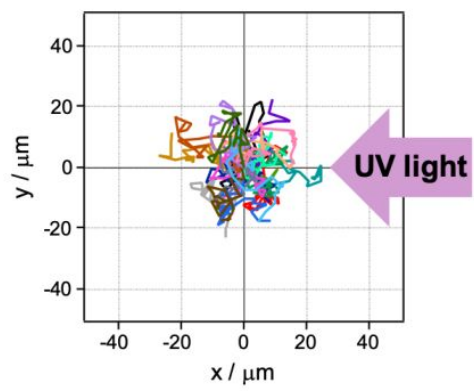

(c) $\mathrm{dA}_{20}-\mathrm{NS}\left(15.6 \mu \mathrm{M} \mathrm{dA} \mathrm{A}_{20}\right)$, +light

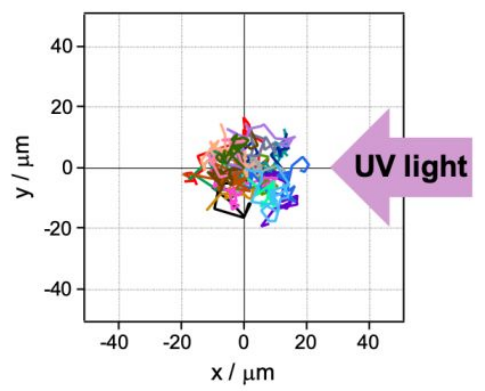

Figure S6. Tracking trajectories of (a) 3-NS with $3.1 \mu \mathrm{M}$ conjugate 3, (b) 3-NS with $0.31 \mu \mathrm{M}$ conjugate 3, and (c) $\mathrm{dA}_{20}-\mathrm{NS}$ with $15.6 \mu \mathrm{M} \mathrm{dA}_{20}$. The trajectories were recorded during $13 \mathrm{~min}$ and UV light irradiation lasted for 5-8 min of recording. Each color represents a different nucleospheres $(N=20)$.

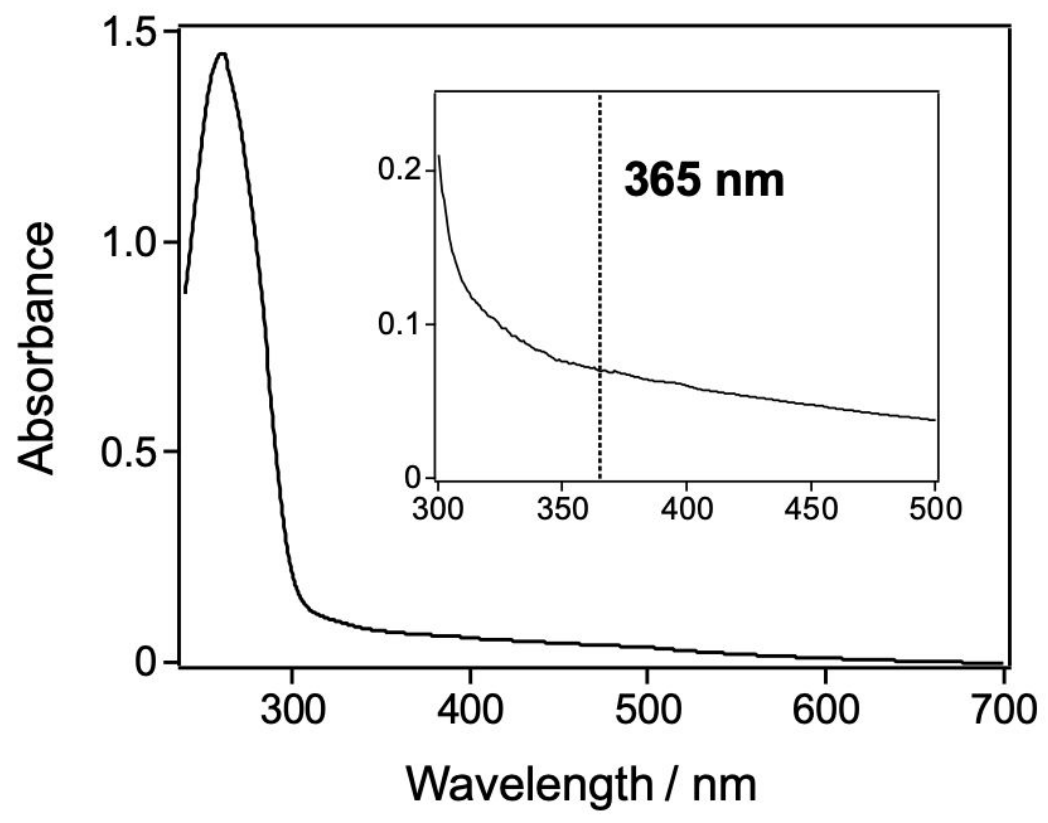

Figure S7. UV-vis absorption spectrum of nucleospheres in $0.5 \mathrm{M} \mathrm{NaCl}$ aqueous solution. [Total $\operatorname{ssDNAs}]=6.7 \mu \mathrm{M}$. 
Movie S1. Movement of 3-NS with $15.6 \mu \mathrm{M}$ conjugate 3 under UV light irradiation. UV light irradiation lasted for 5-8 min of recording. The movie is 50 times faster than the original speed. Final concentrations: [Total ssDNAs] $=0.83 \mu \mathrm{M}$, [Streptavidin] $=0.093 \mu \mathrm{M},\left[\mathrm{dT}_{20}\right.$-biotin] $=0.093$ $\mu \mathrm{M}$, and [Conjugate 3$]=15.6 \mu \mathrm{M}$.

Movie S2. Movement of 3-NS with 15.6 $\mu \mathrm{M}$ conjugate 3 in the absence of UV light. The movie is 50 times faster than the original speed. Final concentrations: [Total ssDNAs] $=0.83 \mu \mathrm{M}$, $[$ Streptavidin $]=0.093 \mu \mathrm{M},\left[\mathrm{dT}_{20}\right.$-biotin $]=0.093 \mu \mathrm{M}$, and $[$ Conjugate 3$]=15.6 \mu \mathrm{M}$.

Movie S3. Movement of $\mathrm{dA}_{20}-\mathrm{NS}$ with $15.6 \mu \mathrm{M} \mathrm{dA}_{20}$ under UV light irradiation. UV light irradiation lasted for 5-8 min of recording. The movie is 50 times faster than the original speed. Final concentrations: [Total ssDNAs] $=0.83 \mu \mathrm{M}$, [Streptavidin] $=0.093 \mu \mathrm{M},\left[\mathrm{dT}_{20}\right.$-biotin $]=0.093$ $\mu \mathrm{M}$, and $\left[\mathrm{dA}_{20}\right]=15.6 \mu \mathrm{M}$. 